\title{
Flow forming of thin-walled precision shells
}

\author{
BIKRAMJIT PODDER $^{1}$, PRABAS BANERJEE ${ }^{2}, \mathrm{~K}^{\text {RAMESH KUMAR }}{ }^{1}$ and \\ NIRMAL BARAN HUI ${ }^{2} *_{\mathbb{B}}$ \\ ${ }^{1}$ Defence Research and Development Laboratory (DRDL), Kanchanbagh, Hyderabad, India \\ ${ }^{2}$ National Institute of Technology (NIT), Durgapur, India \\ e-mail: bikramjitpodder@gmail.com; prabasbanerjee@gmail.com; rkkatta@rediffmail.com; \\ nirmal.hui@me.nitdgp.ac.in
}

MS received 6 November 2017; revised 28 May 2018; accepted 7 July 2018; published online 27 November 2018

\begin{abstract}
Flow forming is an innovative form of cold and chipless metal forming process, used for the production of high precision, thin-walled, net-shaped cylindrical components. During this process, the length of a thick walled tube, commonly known as a preform, is increased with a simultaneous decrease in the thickness of the preform without any change in the internal diameter. Forming of the preform is carried out with the help of one or more rollers over a rotating mandrel. By a pre-determined amount of thickness reduction in one or more number of forming passes, the work material is plastically deformed in the radial direction by compression and made to flow in an axial direction. The desired geometry of the workpiece is achieved when the outer diameter and the wall of the preform are decreased, and the available material volume is forced to flow longitudinally over the mandrel. Over the last three and a half decades the flow forming technology has undergone several remarkable advancements. The versatility of the process makes it possible to produce a wide variety of axisymmetric, nearer to the net-shape tubular parts with a complex profile using minimum tooling changes. In this review article, process details of flow forming have been elaborated. The current state-of-the-art process has been described, and future developments regarding research and industrial applications are also reviewed.
\end{abstract}

Keywords. Flow forming; spinning; thin-walled; tooling; power; force; defects.

\section{Introduction}

Flow forming is a modern, mechanized and chip-less spinning method. Until the 1950 s usually spinning was carried out manually [1], where a pivoted pointer is used to shape the metal sheets, and the workpiece used to be attached to one end of a rotating mandrel (figure 1) with the help of tailstock. This method is popularly accepted for manufacturing axi-symmetric, thin-walled and lightweight domestic products. The repeatability of the finished products for this process was found to be very low and depended on the skill of the operator [2]. However, due to the inherent advantages and flexibilities, this method found acceptability even in the aerospace industry. Later on, a hydraulic spinning machine with copying attachments was introduced in the market. As a result, the dependency on the skill of the operator has been decreased gradually. Such mechanization of the spinning process has led to the evolution of mechanically powered flow turning and flow forming machines. All of these three processes, i.e. spinning, flow turning and flow forming primarily belong to the category of 'Rotary

*For correspondence
Incremental Forming Processes'. Some similarities exist between these processes. These are used for the realisation of axi-symmetric components, and rotating mandrels are used to obtain the final shape of the hardware. As point forming is carried out during the execution of these processes forming load requirement is comparatively lesser than various metal forming processes such as forging, deep drawing, extrusion, etc.

'Spinning' is the oldest among these three processes and it requires relatively lesser power among them. In case of spinning, the final shape of the hardware is obtained by deforming the initial raw material into the shape of the rotating mandrel by applying point forces. Thickness reduction of the raw material is unintended in this process, and the diameter of the final hardware is always lesser than the diameter of the initial raw material.

On the other hand, flow turning or shear spinning is the process in which a thicker round or rectangular plate is formed into various shapes viz. conical, parabolic, ogive, and spherical shape over a rotating mandrel (figure 2). In this process, the required reduction in wall thickness is attained by adjusting the roller-mandrel gap, and final thickness is governed by 'Sine Law'. The final wall thickness $\left(\mathrm{S}_{\mathrm{f}}\right)$ (figure 2) is calculated from starting 


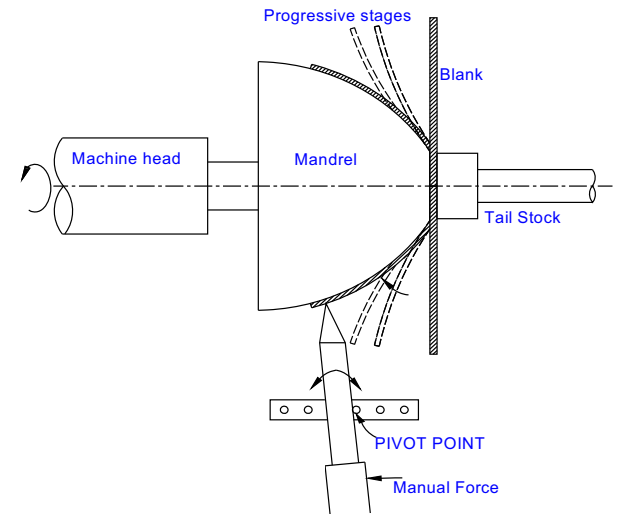

Figure 1. Conventional manual spinning process.

workpiece thickness $\left(\mathrm{S}_{\mathrm{i}}\right)$, and half-cone angle (a) of the mandrel and relationship is expressed as $S_{f}=S_{i} \operatorname{Sin}($ a)

Furthermore, flow forming is the process in which cylindrical workpiece is placed over a mandrel with the help of the rollers (figure 3). The primary difference between flow forming and spinning is that spinning utilizes a relatively thinner piece of starting material, and the final product diameter is always lesser than the starting blank diameter. Whereas, in case of spinning, no reduction of the

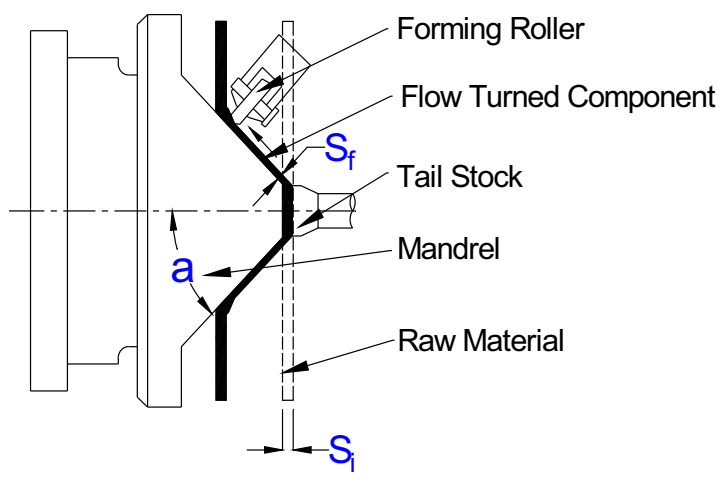

Figure 2. Relationship between initial and final flow turned part thickness.

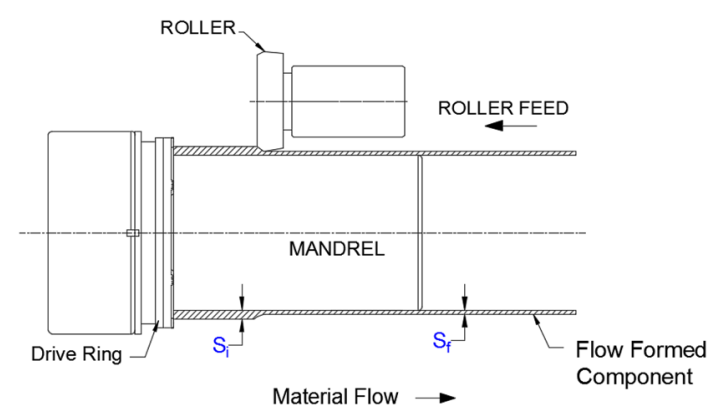

Figure 3. Flow forming operation. workpiece wall thickness is intended though it is challenging to control. Flow forming, on the other hand, is based on a pre-determined decrease of the thickness of the starting blank or preform. Instead of using a pivoted pointer in the form of a roller, the flow forming method uses hydraulically or electrically actuated rollers with automatically controlled movements. The programmed movement of the rollers ensures the flow of workpiece material in the axial and radial direction over the mandrel. Thus, improvement in the accuracy and flexibility over substantial thickness variation are achieved. Some of the products manufactured by spinning and flow forming are rocket motor shells, gas turbine parts, airframe hardware and dish antennas for the aviation industry. In the automobile industry, powertrain components and wheel rims are also manufactured through flow forming process. Gas bottles and cylindrical containers are also made by this method. Though modern spinning machines are capable of producing high forming forces, flow forming machines are much more robust in construction than spinning machines. These machines can generate sufficiently higher forces required to form the metal through its entire thickness. These machines are capable of processing of stronger materials such as ultra-high strength steels and super alloys, etc.

Various metal forming processes are capable of producing cylindrical hardware. Some of these processes are rolling, extrusion, drawing, deep drawing, pilgering, etc. However, none of them can be utilized for the realisation of thin-walled precision shells other than flow forming process. Moreover, flow forming process is capable of producing near net shape hardware with stringent dimensional and form tolerance. Tubes with variable wall thickness, integral external flanges can also be realised through flow forming process. Further, there is no limitation of length to diameter ratio for flow formed tube. Due to these inherent benefits, flow forming process has gained importance primarily in the aerospace, defence and automobile sectors.

Although this process is widely used for the realisation of thin-walled precision cylindrical components, the establishment of suitable flow forming facility is a costly affair. Technical know-how of the process is neither well documented nor readily available in public domain. Requirements of high-cost machinery along with strategic nature of the process limits the usage of the process for a specific purpose only. Though various research works have been published over the years, most of them are confined to a particular aspect of the process. The overview of the process, tooling requirements for the process and significance of each essential process parameters have not been discussed in one place in any of the published literature. Hence, an effort has been made to encompass all of these in the present article. Various experimental as well as numerical modelling techniques used by different researchers to establish input-output relationships for the process, have also been touched. Further, defects of flow formed tube and possible reasons behind it have also been 


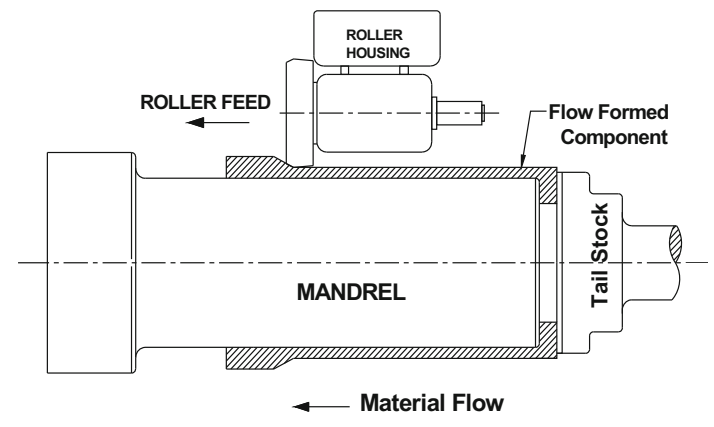

Figure 4. Forward flow forming process.

discussed. The present work attempts not only to fill the voids in published literature domain on flow forming but also to highlight the present research direction in the field.

\section{Types of flow forming}

Two types of flow forming; forward and backward exist in the literature as well as in practice. In case of forward flow forming (figure 4), a tailstock is used to locate the preform over the mandrel, and the elongation of the workpiece takes place along the axial movement of the rollers [3]. The mandrel supports the flow formed tube and length of mandrel must be higher than the flow-formed shell. Forward flow forming is particularly advantageous for components with one end partially or fully closed. In backward (figure 5) flow forming, a toothed ring or drive ring is used to transfer the rotating motion of the mandrel to preform and subsequent elongation of the workpiece takes place in the opposite direction to the axial movement of the rollers. Since, the material flow takes place in the opposite direction of the axial roller movement, the length of the mandrel may be less than the last shell. Usually, during the final pass of the process, some portion of the formed tube comes out of mandrel and remains unsupported during the process. The process is particularly famous for shells with both ends open.

\section{Advantages of flow forming}

Some of the benefits of flow forming process over spinning, deep drawing, sheet metal rolling and welding, are listed below. These advantages are particularly pronounced when components are produced in small or medium size batches.

(i) Low cost in producing components

(ii) Near net shape manufacturing

(iii) Superior surface finish

(iv) Products with excellent accuracy

(v) Enhanced properties in strength of the material

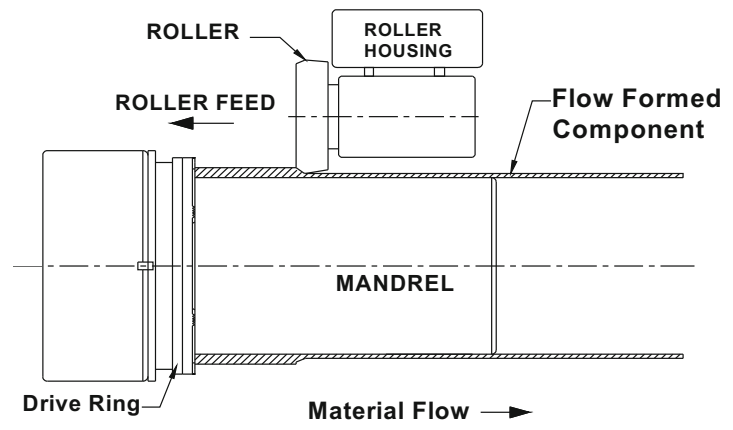

Figure 5. Backward flow forming process.

(vi) Easy cold forming of high tensile strength alloys

(vii) Manufacturing of high precision, thin-walled seamless components

Rotary incremental forming processes such as flow forming process has emerged as a prominent substitute to forging and deep drawing processes, as these processes cannot fabricate complex shape. Flow forming techniques are applied for the production of many critical components, especially for the automotive industry. To enable metal flow in difficult paths using simple tools not only eliminates multi-production stages on presses, thus reducing costs but also offers the potential for the production of lightweight, net shape parts.

\section{Equipment used in flow forming}

Workpiece material is plastically formed over a rotating mandrel during flow forming process using one or more rollers. These rollers are usually hydraulically [4-6] or electrically actuated [7]. Though most of the production flow forming machines are equipped with three rollers (equally spaced $120^{\circ}$ apart), machines with six rollers [8] or four rollers [6] are also available in the market. All of these machines [4-8] are equipped with provisions of axial staggering of rollers. The required axial stagger of the rollers are manually set, depending on thickness reduction and roller geometry. However, most of the research works $[9,10]$ have used single roller flow forming machine for their investigation on flow forming process. Typical brief specification of a three-roller CNC flow forming machine has been reported elsewhere [11].

\section{Tooling used in flow forming}

The tools required for flow forming are a mandrel, stripper ring, toothed ring (usually known as driver ring) and forming rollers. 


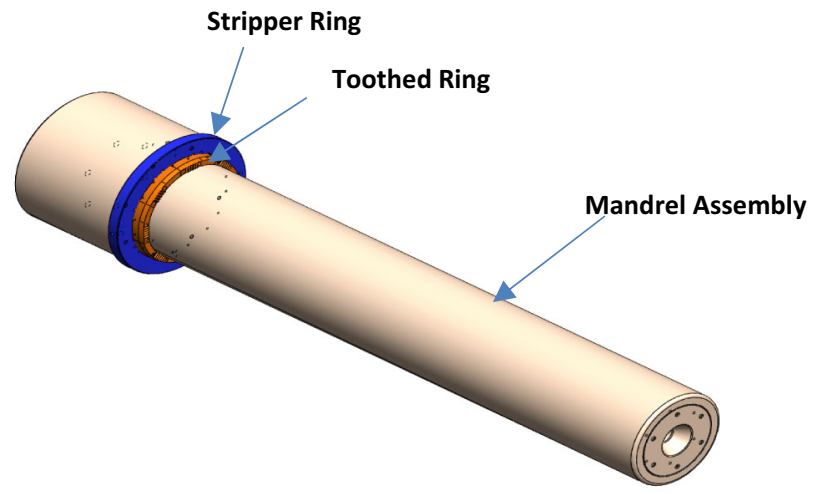

Figure 6. Flow forming mandrel, stripper ring and toothed ring.

\subsection{Mandrel}

The mandrel (figure 6) is the primary tool used for flow forming of any component. The external diameter of the mandrel and internal diameter of the finished component are made equal. The minor taper is provided on the mandrel for easy removal of the element after forming operation. As the accuracy of the component largely depends on the mandrel accuracy, the mandrel is designed with stringent dimensional tolerances. Further, the mandrel is considered as hollow for minimizing the weight and deflection of it. This also facilitates cooling arrangement, which is necessary for removal of heat caused by rapid plastic deformation of the work material. N6 Surface finish is required on the external diameter of the mandrel as it reflects on the internal diameter of the finished tube. The material for the mandrel is considered as AISI D2/D3 [12, 13]. The hardness of the finished mandrel is controlled in between 58 to 62 HRc. This is necessary from rigidity point of view to retain the form accuracy of the mandrel and to protect the mandrel from scratches that may be resulted from actual flow forming operation, preform loading and finished component removal.

\subsection{Stripper ring and toothed ring}

Stripper ring (figure 7) and toothed ring block (figure 8) are two different tools. They are assembled during the actual process. This assembled unit is attached to the flow forming mandrel by a key, placed at the keyway which in turn imparts the same speed to stripper ring and toothed ring as that of the mandrel. Stripper ring is made out of low carbon steel and required to facilitate the removal of the finished tube, and the toothed ring is required to ensure rotation of the preform along with the mandrel, and it is made of AISI D2/D3 steel with a hardness of 58-62 HRc.

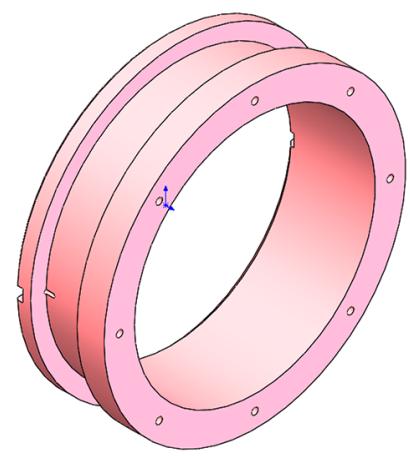

Figure 7. Stripper ring.

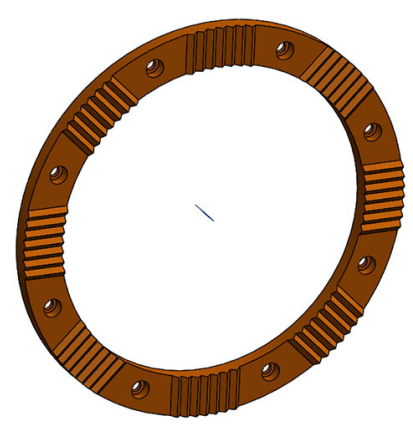

Figure 8. Toothed ring.

\subsection{Roller}

Roller geometry is an essential factor in flow forming, and the roller is subjected to rigorous loading during actual operation. Materials for all the Rollers (figure 9) are considered as AISI D2/D3 having a hardness of 58-62 HRc. The surface finish of the order of N5 or better is preferred on the external profile of the rollers. The essential dimensional parameters of the roller are diameter (D), entry angle $(\alpha)$, tip radius $(\mathrm{R})$ and exit angle $(\beta)$. Flow forming rollers are usually designated as $\alpha / R / \beta$ (figure 10 ). The diameter of the roller is kept as near as possible to the diameter of the mandrel to get enough contact area to ensure uniform deformation. Entry angle and tip radius determine the sharpness of the rollers. Higher entry angle and smaller radius give sharper roller. Sharper rollers exert more deforming force per unit area, thus help in higher reduction per pass and are also suitable for forming high strength materials. In case of axially staggered rollers, the leading roller forms the relatively soft material, and the successive rollers take the work-hardened material. Sharper rollers should be used to deform the worked-hardened material. Exit angle does not have any significant effect on the flow forming process and is chosen between 5 and 12 degrees for all materials. 


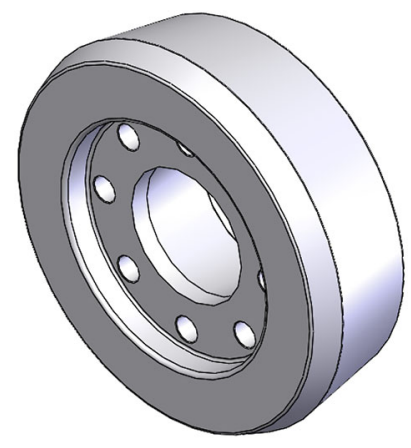

Figure 9. Flow forming roller.

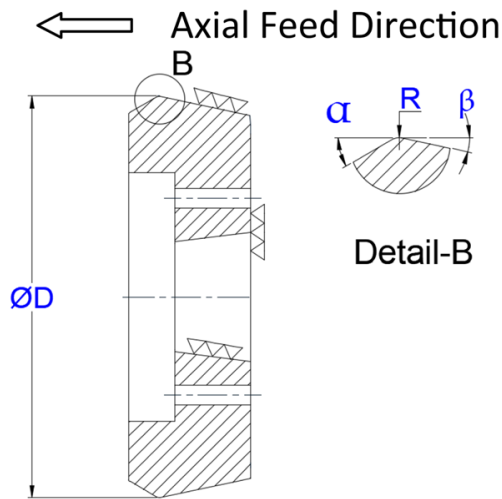

Figure 10. Cross-sectional sketch of flow forming roller.

\section{Fabrication of flow forming tooling}

Mandrel, stripper ring and toothed ring are specific for a given flow formed tube. However, rollers can be selected from the available set of standard rollers, considering material and size of the tube. The tools are subjected to severe loading during operation, and hence, quality requirements of these tools are very stringent right from the raw material stage. A flowchart of a fabrication sequence for mandrel with intermediate inspection stages is given in figure 11 .

\section{Process parameters}

The accuracy of the flow formed component largely depends on the selection of process parameters. Moreover, the process parameters for flow forming is mostly machine dependent. Process parameters established in a specific machine may not yield identical results in some other flow forming machine during forming of the same component. Following are the few vital flow forming process parameters.

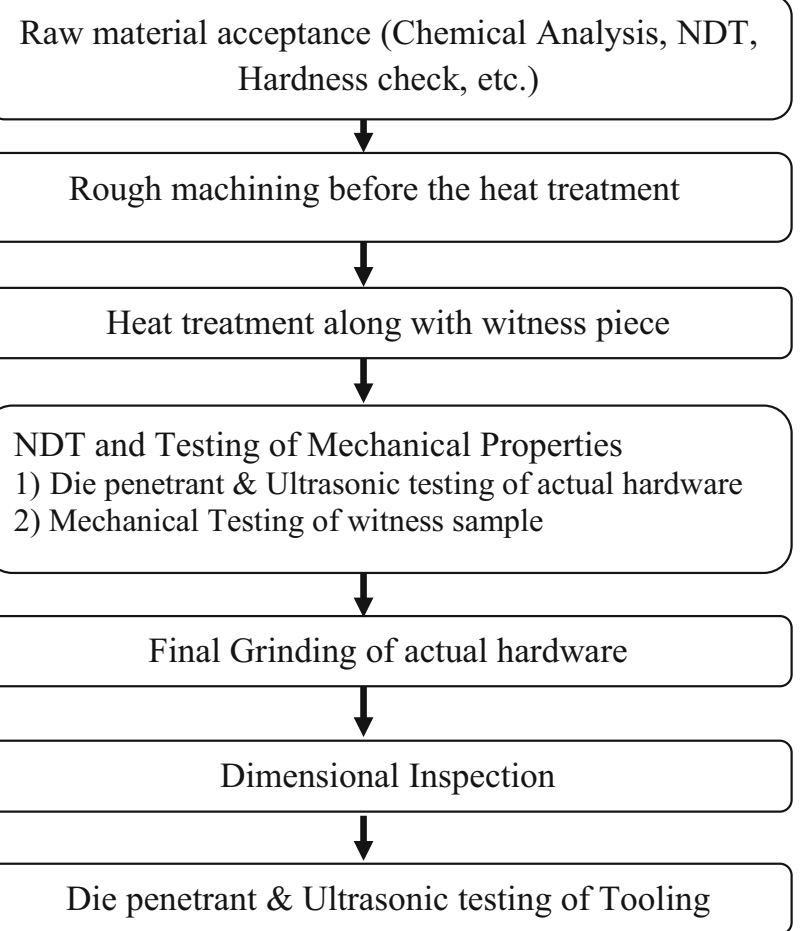

Figure 11. Flowchart for flow forming tooling fabrication.

- Number of forming passes

- Radial compression/thickness reduction per pass

- Roller geometry

- Roller diameter

- Circumferential to axial contact ratio

- Entry/exit angle

- Roller tip radius

- Axial stagger of rollers

- Mandrel speed

- Mandrel span

- Preform thickness and hardness

- Feed rate

- Coolant flow rate

\section{Power and forces}

Spindle power of the flow forming machine and ability of the roller to exert forming forces determine the forming capability of any machine. Hence, estimation of forming forces is essential for selection of process parameters as well as the right machine. In the past few decades, several researchers have undertaken theoretical analyses of power and force in tube spinning. Mohan and Misra [14] have performed a theoretical analysis of the mechanism of plastic flow of tubes using grid-line analysis in various 
working conditions. The useful strains and the forces of roller have been estimated using the plastic work deformation. It has been assumed that the strain during deformation follows a linear path and the strain components in three principal directions can be calculated from the total displacement after distortion. They have carried out their experimental work on commercially pure copper, aluminium and lead. The reported axial, radial and tangential force values were found to be close to the experimental results. Later, Hayama and Kudo [15] have tried to approximate the accuracy of the diameter of the flow formed parts and working forces during the process by using the energy method. They have proposed a unified theory for forward and backward tube spinning considering metal flow in both the processes. Their method produced close results compared to the experimental values over a wide range of working environments such as roller entry angle, feed rate and the reduction in tube thickness. Wang et al [16] have analyzed the mechanics of flow forming using plain strain model and slip-line field theory and estimated the involvement of forces in three-dimensional flow forming. Their results are in good compliance with the findings reported by Hayama and Kudo [15]. In 1990, Singhal et al [17] suggested an equation for the calculation of power required in the spinning of long tubes using upper bound method. They have assumed raw material as perfectly plastic body and forming tools as rigid body. Subsequently they have applied Von Mises Yield criteria to derive the equation of forming forces. They have ignored material build-up so that it applies to both forward as well as backward tube spinning. Further, they have assumed a constant friction factor between the roller and workpiece material and also ignored diametral growth, as hard materials were considered for deriving the expression of power. Park et al [18] used upper bound stream function method to compute the power required in deformation and tangential force. According to them, trapezoidal velocity field has performed well as a stream function in comparison to the spherical velocity field.

Recently, Paunoiu et al [19] proposed a generalised expression based on the upper bound method to calculate flow forming forces. They have divided individual contact zone using different triangular velocity for deformation with flat roller tip as well as a roller with tip radius. In this way, the number of velocity fields could be chosen to ensure more accurate values of forces. Based on their theoretical analysis, they concluded that roller with a flat tip would produce higher force as compared to the roller with tip radius. Jolly and Bedi [20] determined power and forces for manufacturing long thin wall titanium tubes of small bore using upper bound method. They have computed total energy required to form the workpiece material and same has been used for deriving expression for the forming forces. In their analysis they have applied Von Mises Yield criteria and considered workpiece to be perfectly plastic. Further, they found out the reason for increasing trend of power consumption, radial and axial forces with the increase in the thickness reduction. Further, they have concluded that as the diameter of roller increases, more volume of the material comes in contact which leads to increase in higher consumption of power, as well as a rise in axial and radial force.

Process limit and parameters have been determined by Koc and Altan [21] for a hydro-forming process by applying theories of plasticity, membrane and thick-thin walled tube. Prediction of buckling, wrinkling and bursting in hydroformed tube have been carried out analytically, and same have been validated experimentally for simple bulge case. Prediction of axial force, internal pressure, counters force and thinning of a tube at different stages of hydroforming has also been well corroborated with experimental findings. Lee and $\mathrm{Lu} \mathrm{[22]} \mathrm{have} \mathrm{carried} \mathrm{out} \mathrm{force} \mathrm{measure-}$ ment during flow forming of a cylindrical tube made up of a lead of $99 \%$ purity. They have used a rolling die with six rollers for carrying out these experimental studies. Force measurements have also been carried out for both mandrel and rollers by varying deformation ratio and size of the forming rollers under different lubrication conditions. They concluded that forces are not only depended on deformation ratio but also on the size of rollers. Rotarescu [23] has developed analytical expressions to compute deformation contact area during tube spinning using balls. He has considered Von Mises Yield criteria for work material and established systematic relations for computation of work, power, force components and torsional moments. These parameters have also been experimentally obtained with workpiece material such as low carbon steel and Aluminum. Results of analytical expression were found to be in good agreement with the experimental findings. Expression of axial forces $\left(\mathrm{F}_{\mathrm{a}}\right)$, radial force $\left(\mathrm{F}_{\mathrm{r}}\right)$ and tangential force $\left(\mathrm{F}_{\mathrm{t}}\right)$ as derived by Mohan and Misra [14] and Rotarescu [23] have been given in table 1 .

In addition to the above referred analytical techniques, various studies [24-30] have been carried out to predict force and stress distribution during flow forming as well as spinning using finite element methods. Some of them [28-30] have also validated the findings of FE analysis by experimental investigations. Modelling of similar metal forming processes for prediction of material flow, stressstrain distribution, and resultant forces has also been reported elsewhere [31-33].

\section{Effect of process parameters: experimental studies}

The accuracy of flow formed shell largely depends on the selection of process parameters. Several studies [34-37] have been carried out in the past to identify the role of those settings on the accuracy of the flow formed products. Need for considering these parameters has been briefed below. 
Table 1. Expression of forces as derived by researchers [14, 23].

Mohan and Mishra [14]
$F_{t}=\left(t_{i}-t_{f}\right) X f X K_{c} X \frac{\epsilon^{n+1}}{n+1}$
$F_{r}=\left(t_{i}-t_{f}\right) X\left(1-\frac{k}{3 s}\right) \sqrt{\frac{2 R f}{\tan \alpha}} X K_{c} X \frac{\epsilon^{n+1}}{n+1}$
$F_{a}=\left(t_{i}-t_{f}\right) X\left(1-\frac{k}{3 s}\right) \sqrt{2 R f t a n \alpha} X K_{c} X \frac{\epsilon^{n+1}}{n+1}$
$\epsilon=3 \ln \frac{t_{i}}{t_{f}}$
$s=1-\left(\frac{t_{i}}{t_{f}}\right)$
$k=\left(\frac{t_{i}}{t_{f}}\right) \tan \propto$

Rotarescu [23]

$F_{t}=\frac{k A_{t}(4+\pi+2 m)\left[(2 \rho \sin +f) \sin \theta \cos \theta-2 x_{1}\right]}{12 \rho}$

$F_{r}=\frac{k A_{r}(4+\pi+2 m)\left(2 z_{1}+2 \rho \cos +\sqrt{4 \rho^{2}-f^{2}}\right)}{12 \rho}$

$F_{a}=\frac{k A_{a}(4+\pi+2 m)\left(2 y_{1}+2 \rho \sin \cos \theta-f\right)}{12 \rho}$
$\mathrm{t}_{i}$-Initial thickness of the preform (mm)

$\mathrm{t}_{f}$-Final thickness of the preform $(\mathrm{mm})$

$f$-Feed rate $(\mathrm{mm} /$ rev)

$\alpha$-Roller entry angle

$n$-Strain hardening exponent of raw material

$K_{c}$ - Strength co-

efficient of raw material

$R$-Roller radius (mm)

$A_{t}$-Projected area of deformation volume in tangential plane

$A_{r}$-Projected area of deformation volume in radial plane

$A_{a}$-Projected area of deformation volume in axial plane

$k$-Shear flow stress

$m$-Shear friction co-efficient $\rho$-Contact deformation pressure

$\alpha$-Roller entry angle

$f$-Feed rate

$\theta$-Angle of outer

helical trajectory/ halix angle

$x_{1}, y_{1}, z_{1}$-The distance of

highest point of the deformation arc (located on work piece outer surface) from the roller centre when measured along tangential plane, axial plane and radial plane respectively
Table 2. Variation of ovality and mean diameter for different roller radius [34].

\begin{tabular}{lcc}
\hline Roller radius & Ovality & Mean diameter \\
\hline 4 & 0.10 & 42.10 \\
8 & 0.45 & 43.50 \\
10 & 0.86 & 43.80 \\
12 & 1.32 & 44.30 \\
15 & 0.98 & 45.50 \\
\hline
\end{tabular}

\subsection{Roller radius}

Effect of roller radius was studied by Srinivasulu et al [34] by conducting experiments with different rollers of radius 4 to $15 \mathrm{~mm}$. They observed that ovality of the tube directly proportional to the roller radius. They opined that less force is produced with smaller roller radius, resulting in lesser ovality in the tubes. They also have mentioned that the increase in the mean diameter of the tube is directly proportional to the roller radius (refer to table 2). According to them, increase in roller radius increases the radial force during forming, leading to increasing circumference dimension and resulting in increased mean diameter. Their experimental results, i.e., the variation in ovality and increase in mean diameter with roller radius are presented in table 2.

\subsection{Mandrel speed}

Lower mandrel speed produces scratch marks on the tube surface, whereas higher speed up to a certain limit results in smooth finish [9]. The finish of flow formed shell deteriorates above specific limiting value of mandrel speed due to vibrations at higher speed (figure 12). Davidson et al [9] observed the phenomenon in their experimental studies. They have found that higher mandrel speed unifies the surface avoiding few defects on the surface. At extreme high-speed machine generated vibration leading to decreased surface qualities. They have further opined that enormous increase in speed leads to increase in adiabatic temperature of the preform, causing plastic instability of the material.

\subsection{Feed rate}

Srinivasulu et al [34] carried out experiments by varying the feed rates. During their studies, they found that lower feed rates resulted into tubes with larger inner diameter. They opined that at lower feed rate plastic deformation in an axial direction is slower than the radial direction. This leads to material deformation in the radial direction compared to axial, resulting in an opening of the internal diameter of the tube. Davidson et al [9] have carried out experiments with different feed rates. They have further 


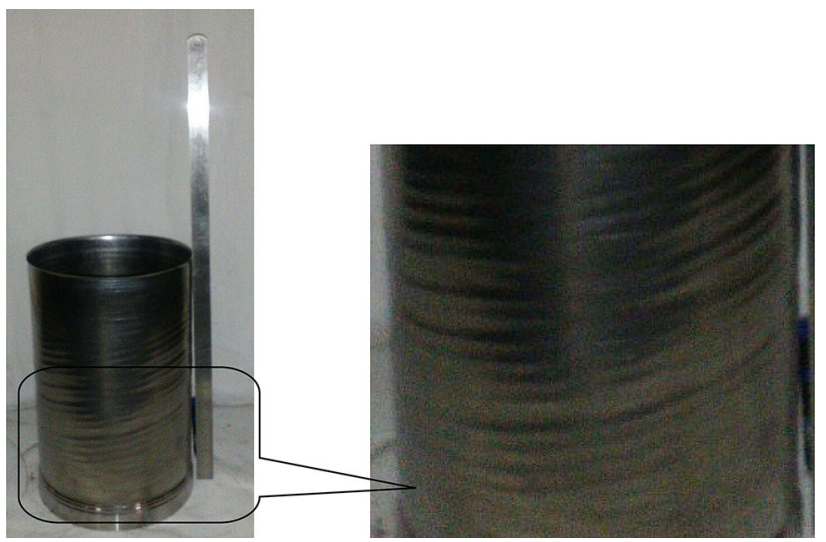

Figure 12. Flow-formed tube with vibration marks.

found that higher feed rate produced a wave-like surface. They have opined that at a high feed rate, the roller moves quicker by rejecting plastic deformation and in combination with heavier thickness reduction, it leads to wavy flow formed tube surface. In general, a balance has to be maintained between the feed rate, a thickness of blank and roller profile to achieve proper flow and desired surface finish of flow formed product [35]. Meagre value of feed rate for a particular blank thickness results into deformation in a radial direction, leading to increasing the internal diameter of the preform. For such low feed rates, defects such as non-uniform thickness, increase in diameter as well as a rough surface would occur.

\subsection{Thickness reduction}

Davidson et al [9] opined that an optimized thickness reduction is essential for a suitable surface. Workpiece gets strain hardened which develops surface defects such as fish scaling. Non-uniform deformation is also observed in the workpiece due to very less thickness reduction. In such cases, the surface layers are subjected to higher deformation compared to the low deformation at the contact surface with the mandrel. It ultimately results in initiation of cracks on the tube wall. A tube with such crack is shown in figure 13 . On the other hand, very high thickness reduction causes final tube surfaces marked with roller profiles of highly strained magnitude.

Similar findings on effects of thickness reduction have been observed by other researchers [34]. They have also reported surface crack due to smaller thickness reduction. Molladavocedi and Djavanroodi [36] concluded that geometrical accuracy of flow formed tube deteriorates with increase in thickness reduction. Further, they have observed an increase in diameter growth with an increase in thickness reduction. Some researchers [37] concluded that better surface finish in Aluminum 2024 tubes is obtained due to higher percentage of thickness reduction, increase in

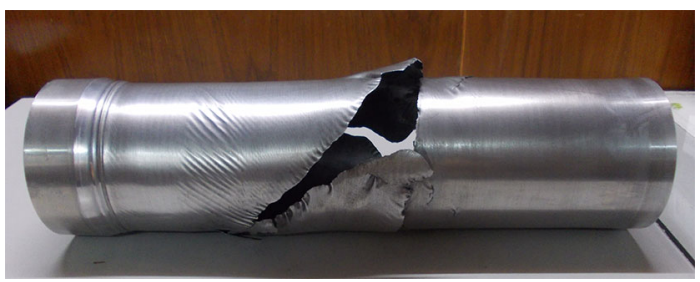

Figure 13. Surface cracks in flow formed tube.

solution and ageing treatment time, less feed rate and minor speed of the mandrel.

\subsection{Ratio of circumferential to axial contact}

Flow forming often results into waviness or bulges on the outer surfaces of the shells [38]. Such phenomenon is termed as 'plastic flow instability'. Gur and Tirosh [38] have studied this 'plastic flow instability' during tub spinning process and observed that the ratio of the circumferential length of contact (S) and the axial length of contact (L) under the roller is one of the critical parameters in this regard. The plastic flow instability which results in wavy bulges on the outer surface of the finished component is influenced by this ratio [38]. With an increase in attack angle/roller entry angle, the ratio increases and combined with the friction at the interface, the material tends to flow in the axial direction. This results into a tube with better circularity, whereas a small ratio results into a shell with geometrical inaccuracies. Contrary to that, very large circumferential to axial contact ratio will lead to flow of metal at an angle less than the attack angle, resulting in waviness along the surface and non-uniform thickness. Similarly, high attack angle will increase the power requirement and decrease the efficiency of the forming process. Therefore, an optimum combination of the percentage reduction and attack angle is essential to ensure flow formed shell accuracies. Several researchers have computed and used S/L ratio in their investigations. Jahazi and Ebrahimi [35] have concluded the $S / L$ ratio depends on entry angle $(\alpha)$ of roller and percentage of thickness reduction. Further, the ratio works as an indicator of flow forming defects. Podder et al [39] have computed S/L ratio for their investigated combination of percentage of thickness reduction, feed-speed ratio and roller entry angle during flow forming of AISI4340 steel.

Several other researchers [40-43] have carried out experimental investigations to study the effects of various parameters on the final flow formed tube. Malina et al [40] have carried out viability check on the realisation of $16 \mathrm{MnCrS} 5$ steel tube through flow forming process. In this experimental work, the effect of raw material annealing time and variation of feed-speed ratio on the hardness, mechanical strength and surface finish of flow formed tube 
has been examined. Rao et al [41] have studied the effect of feed rate on the quality of flow formed Maraging steel tube. Mean diameter, ovality, tube thickness and finish of internal and external surface of the flow formed tube have been analyzed by them as output parameters. Effect of roller tip radius, stagger, preform hardness variation and feed rate on flow formed tube properties have been experimentally analysed by Bairaju et al [42]. They have found that mean diameter and ovality of the flow formed tube is directly proportional to roller tip radius. Further increase of mean diameter and ovality of the flow-formed tube with an increase in roller stagger has also been reported by them. From their experimental result, it is also evident that thickness variation of flow formed tube are directly proportional to the preform hardness variation. Effect of mandrel speed and feed rate on surface finish and spring back of spun AA19500 cup has been analysed by Venkateswarlu et al [43]. Experimental details of these researchers have been summarized in table 3. Further, the impact of different process parameters on the flow-formed tube has been summarized in the following table 4 .

\section{Modelling of the process using the design of experiments (DOE) and study of the effects of process parameters}

Several investigators have used DOE as a tool to establish the relationship between input and output of flow forming process. Thus, they have established cause and effect relationship between input and output parameters and tried to identify significant input parameter. Davidson et al [44] have used Taguchi Orthogonal Array to identify critical input parameter affecting the percentage of length elongation during flow forming of the AA6061 alloy. They have selected thickness reduction, mandrel speed and feed rate as input parameters and three levels of each of these parameters have been used for experimentations. Further, they have used ANOVA to quantify relative significance of each of these input parameters. They have concluded that thickness reduction is the most critical parameter affecting the percentage of length elongation during flow forming of AA6061 alloy tubes. Srinivasulu et al [10] have adopted Box-Behnken design to develop a regression model to predict internal diameter of flow formed AA6082 tube. They have used roller radius, mandrel speed and feed rate as input parameters and considered two levels for each of these parameters during experimentation. They have concluded that roller radius and feed rate are having most significant contributions in controlling the internal diameter of flow formed shell.

The influence of significant process parameters such as preform thickness, the percentage of thickness reduction, mandrel speed, feed rate, solution ageing time on process time and wall thickness changes for fabrication of AA2024
Table 3. Summary of experimental works on effects of process parameters [40-43].

\begin{tabular}{|c|c|c|c|}
\hline Author(s) & Aim of study & $\begin{array}{c}\text { Input } \\
\text { variable (no. } \\
\text { of levels) }\end{array}$ & $\begin{array}{l}\text { Output } \\
\text { variable }\end{array}$ \\
\hline Malina et al [40] & $\begin{array}{l}\text { Viability } \\
\text { check for } \\
\text { steel tube } \\
\text { realization }\end{array}$ & $\begin{array}{r}\text { Annealing } \\
\text { time (2) } \\
\text { Feed-speed } \\
\text { ratio (3) }\end{array}$ & $\begin{array}{l}\text { Hardness, } \\
\text { mechanical } \\
\text { properties } \\
\& \text { surface } \\
\text { finish }\end{array}$ \\
\hline Rao et al [41] & $\begin{array}{l}\text { Effects of } \\
\text { process } \\
\text { parameters } \\
\text { on flow } \\
\text { formed } \\
\text { tube } \\
\text { geometry }\end{array}$ & Feed rate $(5)$ & $\begin{array}{l}\text { Mean } \\
\text { diameter, } \\
\text { Ovality, } \\
\text { Finish of } \\
\text { internal and } \\
\text { external } \\
\text { tube } \\
\text { surface, } \\
\text { Tube } \\
\text { thickness }\end{array}$ \\
\hline Bairaju et al [42] & $\begin{array}{l}\text { Effects of } \\
\text { process } \\
\text { parameters } \\
\text { on flow } \\
\text { formed } \\
\text { tube } \\
\text { geometry }\end{array}$ & $\begin{array}{c}\text { Roller tip } \\
\text { radius (4), } \\
\text { Stagger } \\
(3), \\
\text { Preform } \\
\text { hardness } \\
\text { variation } \\
(4), \text { Feed } \\
\text { rate (5) }\end{array}$ & $\begin{array}{l}\text { Mean } \\
\text { diameter, } \\
\text { Ovality, } \\
\text { Finish of } \\
\text { internal and } \\
\text { external } \\
\text { tube } \\
\text { surface, } \\
\text { Tube } \\
\text { thickness }\end{array}$ \\
\hline $\begin{array}{l}\text { Venkateshwarlu } \\
\text { et al }[43]\end{array}$ & $\begin{array}{c}\text { Effects of } \\
\text { process } \\
\text { parameters } \\
\text { on surface } \\
\text { finish and } \\
\text { spring back }\end{array}$ & $\begin{array}{l}\text { Mandrel } \\
\text { speed (3), } \\
\text { Feed rate } \\
\quad(3)\end{array}$ & $\begin{array}{r}\text { Surface finish, } \\
\text { Spring-back }\end{array}$ \\
\hline
\end{tabular}

tubes has been studied by Nahrekhalaji et al [45]. They have investigated the effect of input parameters using DOE and analysed the experimental data with ANOVA. Thus, they have developed statistical regression equation of thickness changes and process time. Davidson et al [46] have developed surface roughness prediction model for flow forming of the AA6061 tube considering the speed of the mandrel, feed rate and amount of coolant used. Effects of input parameters were studied using the design of experiments, and BoxBehnken design has been applied to establish the response surface design. Further, ANOVA analysis has been carried out to ascertain the adequacy of the model terms on the response parameter. Abedini et al [47] have studied the effect of various flow forming parameters on the roughness of the outer surface of flow formed tube. Effects of input parameters such as thickness reduction, feed rate, roller tip radius, etc. have been critically analysed using Taguchi technique. Results of ANOVA analysis confirm roller tip radius as most crucial parameter effective tube surface finish followed by thickness reduction ratio. Aghchai et al [48] 
Table 4. Effects of process parameters on the shape accuracy of flow formed tube.

\begin{tabular}{|c|c|c|c|}
\hline Parameter & Ovality & $\begin{array}{c}\text { Mean } \\
\text { diameter of } \\
\text { tube }\end{array}$ & $\begin{array}{c}\text { Surface } \\
\text { roughness of } \\
\text { outer surface }\end{array}$ \\
\hline $\begin{array}{l}\text { Roller } \\
\text { radius }\end{array}$ & $\begin{array}{l}\text { Directly } \\
\text { proportional }\end{array}$ & $\begin{array}{l}\text { Directly } \\
\text { proportional }\end{array}$ & $\begin{array}{l}\text { Inversely } \\
\text { proportional }\end{array}$ \\
\hline Feed rate & $\begin{array}{l}\text { Inversely } \\
\text { proportional } \\
\text { up to a } \\
\text { limiting } \\
\text { value }\end{array}$ & $\begin{array}{l}\text { Inversely } \\
\text { proportional }\end{array}$ & $\begin{array}{l}\text { Directly } \\
\text { proportional }\end{array}$ \\
\hline $\begin{array}{l}\text { Thickness } \\
\text { reduction }\end{array}$ & Negligible & $\begin{array}{l}\text { Inversely } \\
\text { proportional }\end{array}$ & $\begin{array}{l}\text { Directly } \\
\text { proportional }\end{array}$ \\
\hline $\mathrm{S} / \mathrm{L}$ ratio & $\begin{array}{l}\text { Inversely } \\
\text { proportional }\end{array}$ & $\begin{array}{l}\text { Inversely } \\
\text { proportional }\end{array}$ & Negligible \\
\hline $\begin{array}{r}\text { Mandrel } \\
\text { speed }\end{array}$ & $\begin{array}{l}\text { Inversely } \\
\text { proportional }\end{array}$ & $\begin{array}{l}\text { Directly } \\
\text { proportional }\end{array}$ & $\begin{array}{l}\text { Inversely } \\
\text { proportional } \\
\text { up to a } \\
\text { limiting } \\
\text { value }\end{array}$ \\
\hline
\end{tabular}

have investigated the effect of percentage of thickness reduction, the feed rate of roller and roller tip radius on the diametric growth during flow forming of AISI 321 steel tube. They have used Response Surface Methodology to develop a mathematical model of diametric growth concerning significant input parameters. They concluded that the percentage of thickness reduction is the most significant parameter whereas the feed rate is having the minimum effect on diametric growth.

Different researchers $[9,49-52]$ have applied various Design of Experiment (DOE) techniques for modelling of flow formed as well as other rotary incremental forming process. Chen et al [49] have used Taguchi method for optimization of inner rib thickness during simulation of the neck-in process of the AA6061-T6 alloy. They have used mandrel support span, mandrel speed, feed rate and roller diameter as input/control variable and adopted $\mathrm{S} / \mathrm{N}$ ratio, response chart and average response chart method for optimization of the inner rib. Razani et al [50] have used Taguchi method for optimization of out of roundness of flow formed AISI321 steel tube. They have used feed rate, thickness reduction and roller entry angle as input parameter and attempted to minimize out of roundness of flow formed AISI 321 steel tube. Same authors [51] have subsequently used Response Surface Method (RSM) to optimize hardness of flow formed AISI 321 steel tube. Modeling of a paraxial spinning process using Taguchi method has been attempted by Guo et al [52]. They have tried to predict outer diameter, surface finish and the final thickness of flow formed Ni-based superalloy tube considering roller tip radius, mandrel speed and feed rate as input parameters. Davidson et al [9] have modelled hardness of flow formed and artificially aged AA 6061 tube using Response Surface Method considering solutionising time, ageing time and ageing temperature as input parameters in their model. A summary of the research studies $[9,49-52]$ are presented in table 5 .

\section{Modelling of the process using finite element methods (FEM) and study of the effects of the process parameters}

Considerable research has been carried out on modeling of flow forming process using FEM, and some of them have been described in this section. Wong et al [53] used explicit FE to analyse the forming of solid cylindrical preform using

Table 5. Summary of application of DOE approaches on flow forming and similar rotary incremental process [9, 49-52].

\begin{tabular}{|c|c|c|c|c|c|}
\hline Author(s) & Aim of study & $\begin{array}{l}\text { DOE } \\
\text { methods }\end{array}$ & $\begin{array}{l}\text { Input variable (no. of } \\
\text { levels for each) }\end{array}$ & Output variable & Evaluation method \\
\hline $\begin{array}{l}\text { Chen et al } \\
\text { [49] }\end{array}$ & $\begin{array}{l}\text { Optimization of rib } \\
\text { thickness during neck-in } \\
\text { spinning process }\end{array}$ & $\begin{array}{l}\text { Taguchi } \\
\text { method }\end{array}$ & $\begin{array}{c}\text { Mandrel span, Mandrel } \\
\text { speed, feed rate and } \\
\text { diameter (3) }\end{array}$ & Rib thickness & $\begin{array}{c}\mathrm{S} / \mathrm{N} \text { ratio, response } \\
\text { chart, average } \\
\text { response chart }\end{array}$ \\
\hline $\begin{array}{l}\text { Razani } \\
\text { et al } \\
\text { [50] }\end{array}$ & $\begin{array}{c}\text { Optimization of out of } \\
\text { roundness }\end{array}$ & $\begin{array}{l}\text { Taguchi } \\
\text { method }\end{array}$ & $\begin{array}{l}\text { Feed rate, Thickness } \\
\text { reduction, Roller entry } \\
\text { angle (3) }\end{array}$ & $\begin{array}{l}\text { Out of roundness of flow } \\
\text { formed AISI321 steel } \\
\text { tube }\end{array}$ & ANOVA \\
\hline $\begin{array}{r}\text { Razani } \\
\text { et al } \\
\text { [51] }\end{array}$ & Optimization of hardness & $\begin{array}{r}\text { Response } \\
\text { surface } \\
\text { method }\end{array}$ & $\begin{array}{l}\text { Mandrel speed, Feed rate, } \\
\text { Thickness reduction (2) }\end{array}$ & $\begin{array}{l}\text { Hardness of flow formed } \\
\text { AISI } 321 \text { steel tube }\end{array}$ & ANOVA \\
\hline $\begin{array}{l}\text { Guo et al } \\
\text { [52] }\end{array}$ & $\begin{array}{l}\text { Modelling of paraxial } \\
\text { spinning process }\end{array}$ & $\begin{array}{l}\text { Taguchi } \\
\text { method }\end{array}$ & $\begin{array}{l}\text { Roller tip radius, Mandrel } \\
\text { speed, Feed rate (3) }\end{array}$ & $\begin{array}{l}\text { Outer diameter, surface } \\
\text { finish and final } \\
\text { thickness }\end{array}$ & ANOVA \\
\hline $\begin{array}{l}\text { Davidson } \\
\quad \text { et al [9] }\end{array}$ & $\begin{array}{l}\text { Modelling of hardness of } \\
\text { artificially aged tube }\end{array}$ & $\begin{array}{r}\text { Response } \\
\text { surface } \\
\text { method }\end{array}$ & $\begin{array}{c}\text { Solution time, aging time } \\
\text { and temperature (2) }\end{array}$ & $\begin{array}{l}\text { Hardness of flow } \\
\text { formed, artificially } \\
\text { aged AA6061 tube }\end{array}$ & ANOVA \\
\hline
\end{tabular}


ABAQUS software and analyzed the effect of mass scaling on dynamic properties of the process. The following assumptions were considered by them in the model to reduce computational complexity:

- The workpiece material was assumed to be an elastoplastic material.

- Roller and mandrel both were modelled as rigid part geometries.

- The work-piece rotation was not considered.

- The roller was rotated around the axis of the rotating workpiece with the similar speed as in the experimental process.

- The friction between the workpiece and roller was assumed as the friction factor $\mu$, which they have defined as $\zeta=\mathrm{k}=\sigma / \sqrt{ } 3$ where $\zeta$ is the shear stress, $\mathrm{k}$ is the shear strength, and $\sigma$ is the flow stress of the material.

The model proposed by Wong et al [53] was successful in predicting the stress and strain generated during the forming process. The authors also concluded that the rollers geometry plays a dominating role in shaping the deformed product, but work-piece with an initial thickness of $10 \mathrm{~mm}$ needs higher machine capability and high mandrel rigidity to avoid any bulging phenomenon. The assumption made in the research work can be implemented in solving complex flow forming problems. Li et al [54] developed a 3D FE program to model the stress-strain effects in the deformation zone in tube spinning. The tube was modelled to rotate along with the mandrel, and the rollers were given axial feed. The results obtained were used in determining the ovality and bell mouth defects related to tube spinning.

Song et al [55] have studied the diametric growth of tube during forward flow forming process using commercial FE implicit code, DEFORMTM 3D V10.0. They have carried out an experimental investigation as well as finite element simulation using implicit investigation scheme. AA6061 and SS304 have been considered as experimental material, and residual stresses of the formed products were measured using X-ray diffraction technique. They could obtain good agreement between the simulation and experimental results. Cho et al [56] have developed an approximate finite element analysis model for simulation of flow forming process. They have considered two fixed artificial planes of symmetry and constrained their analysis domain within them. Two analysis domains of 1/24th and 1/8th of full domain size have been considered, and simulation results were compared with the experimental results. Though the results of an artificial plan of symmetry were found to be entirely different, results of midplane region were found to be in good agreement with the experimental results. Further, they have opined that predictions of a 1/24th domain model are more reliable as it has been built with finer mesh system. Shinde et al [57] have used ABAQUS/explicit to develop a 3D thermo-mechanical finite element model for reverse flow forming of a cylindrical workpiece made up of maraging steel. They have studied the effect of feed rate and thickness reduction ratio on stress/strain distribution and roller forces. Further, they have carried out a parametric study to ascertain the effect of process parameters on ovality, diametral growth, roll forces, stress and strains. They have concluded that feed rate, thickness reduction ratio and roller entry angle are the most significant parameters controlling the circularity of the flow formed tube.

Novella et al [58] have developed an optimised finite element based model for numerical simulation of flow forming of AlSi7 alloy at elevated temperature. Implicit solution scheme with an arbitrary Lagrangian-Eulerian meshing has been adopted during the development of the model. The influences of input process parameters such as thickness reduction, feed rate and mandrel speed have been studied, and finally, an algorithm for derivation of parametric process chart has been proposed.

Hauk et al [59] implemented both 2D and 3D FE analysis for the simulation of both flow splitting process considering disk type workpiece. For the 2D model, an axi-symmetric method was assumed and compared the results obtained from the commercial FE-code through DEFORM-3D and MARC/Autoforge. The approach adopted by the authors can efficiently solve axi-symmetric problems (for example, rolling of billet with two rollers).

Hua et al [60] made a three-dimensional elasto-plastic FE analyses with the help of ANSYS software of three roller backward tube flow forming. The authors were successful in establishing the contact pair not only between workpiece and rollers but also between mandrel and workpiece. It was suggested that the rollers feed rate, the speed of the mandrel and thickness reduction are the primary process parameters and complex state of axial and circumferential stresses formed in the flow formed tubes leads to surface cracks. According to their report, the influence of feed rates was found to be maximum for flowforming of AA7075 tubes.

Razavi et al [61] used ABAQUS explicit 6.4 to simulate the spinning process. The following assumptions were considered in their study to reduce the computational complexity.

- The friction coefficient between a tool and the workpiece interface was assumed as 0.02 .

- The frictionless interface was assumed between the workpiece and mandrel.

- The tailstock was not considered in the simulation to reduce computational time. The blank was segregated into two separate cells using a central cylindrical cell of radius $26.5 \mathrm{~mm}$ and constrained to the mandrel.

They concluded that hoop and radial strains in FE-simulations are close to the experimental values of a spinning process. They also have opined that the stress developed on the inner surface of the workpiece is very low, but it plays a significant role in bellmouth formation in tubes. 
Sebastiani et al [62] worked on 3D FE simulation of the sheet metal spinning process to generate the process plan and the stresses attained during the process. The simulated results were based on an explicit code-named LS-Dyna. The research emphasizes the complexity to simulate the spinning process as there was a need to model the entire workpiece even if a small part of the workpiece was in contact with the roller at any instant of time. Springback was not investigated as authors suggested that springback has minimal effect on the final geometry of the work-piece. Parsa et al [63] stated that material parameters were significant factors during any forming operation and it defines the formability of the preform. The tube was modelled as deformable and classical bi-linear isotropic hardening model was chosen. Emphasis was given to determine the S-L ratios which were proportional to attack angle i.e., entry angle of the rollers and feed rate. The authors developed their own explicit FEA code in Matlab and concluded that their developed code could effectively attain better solution and a good correlation exists between feed rates and axial velocities in incremental forming processes.

Xintian et al [64] used FE-modeling to demonstrate rolling deformation in inner spline and identified proper feed rates and forces necessary for shaping the spline. A 3D model was created initially in CAD software, which is then used to develop the FE model in ABAQUS Explicit. They observed that forward speed of the rollers determines the direction of metal plastic flow. To ensure the maximum usage of material and inner spline teeth, material flow needs to be stopped at the end of each tooth.

Qian et al [65] made a 3D FE model of power spinning having small wall thickness using ABAQUS. Thin-walled Aluminium shell with inner rib was modelled by two ways. Firstly, using cutting in which there is wastage of material and later on, changing the mandrel structure. This makes the flow line of the metal distributed along the workpiece. As a result, strength, fatigue property and corrosion resistance of the workpiece improved significantly. Quigley and Monaghan [66, 67] addressed some difficulties regarding the FE modeling of a metal spinning process. Some challenges such as mesh definition, time steps or increments, tool paths were identified and studied. To overcome the said problems, they $[66,67]$ used the adaptive meshing technique and the constraint contact algorithm.

Wong et al [68] have used ABAQUS Explicit and Implicit for modeling of flow forming of solid cylindrical components. They have considered roller geometry and feed rate as input parameter and predicted forming load and material flow characteristics. Chen et al [69] have attempted modeling of spin forming of D6AC alloy tube using ANSYS/LS Dyna. They have tried to simulate spinning forces, stresses as well as strain. Modeling of flow forming of Aluminum alloy 6060 tubular structure has been carried by D'Annibale et al [70] using PAM-STAMP. They have simulated axial elongation, external diameter, final tube thickness, temperature distribution and Von-Mises stress considering feed rate and thickness reduction as input parameters. SHAPE-RR has been used by Hwang et al [71] for prediction of bulging during Aluminum wheel forming. They have considered headstock load (Axial force), radial compression (thickness reduction) and geometry of rollers as inputs to their developed model. Contributions made by the researchers in [68-71] are summarized in table 6.

Houillon et al [72] used two different Finite Element codes based on Forge simulation software FORGE 2005. The first is based on self-contact management algorithm where updated Lagrangian formulation is used. In the second code, ALE method is used for optimizing meshing with the help of Zienkiewicz-Zhu error estimation. In updated Lagrangian formulation, same initial mesh cannot be used for the whole problem, re-meshing after distortion of the initial meshes needs to be done. This leads to more computational resources. Both formulations are coupled with tool kinetics. The ALE technique is found to perform better compared to the Lagrangian formulation with regard to computational time and simulation of simple configurations.

\section{Defects in flow forming}

Rajan and Narasimhan [73] have investigated the reasons for defects generation, and failure occurrence in flow formed SAE 4130 thin wall steel tubes. The significant defects observed during their study include fish scaling, diametral growth, early burst, macro and microcracks. It has been further observed that the metallurgical or material defects present in raw material such as inclusions and variation in grain structure may lead to defects in flow formed shell.

\subsection{Plastic flow instability}

Wavy surface often develops on the outside surface of the tube. Defects such as this result due to "plastic flow instability" [38]. Sortais et al [74] investigated instability during cone spinning. He established a relationship between the wrinkles on the pre-spun flange of the cone with the residual compressive stress. Such plastic flow instability is also seen in deep drawing processes. Gur and Tirosh [38] investigated the reason and commented that higher circumferential length of contact (S) to the axial length of contact (L) ratio is the main reason behind such phenomenon. Diametral growth and forming of bulges are one of the frequent troublesome issues in flow forming. Diametral growth is influenced by the ratio of the circumferential contact length (S) to the axial contact length (L). Better diameter control is possible for a proper S:L ratio [38]. Experimental investigation on flow formed AISI 4130 steel by backward forming revealed that the diametral growth is directly proportional to percentage of thickness 
Table 6. Summary of application of finite element methods on flow forming [68-71].

\begin{tabular}{|c|c|c|c|c|c|}
\hline Author(s) & Aim of study & $\begin{array}{l}\text { Software } \\
\text { used }\end{array}$ & Input variable & Output variable & $\begin{array}{l}\text { Experimental } \\
\text { validation }\end{array}$ \\
\hline $\begin{array}{l}\text { Wong et al } \\
\text { [68] }\end{array}$ & $\begin{array}{c}\text { Modelling of flow forming } \\
\text { of solid cylindrical } \\
\text { component }\end{array}$ & $\begin{array}{l}\text { ABAQUS } \\
\text { Explicit } \\
\text { and } \\
\text { Implicit }\end{array}$ & $\begin{array}{l}\text { Roller geometry, feed } \\
\text { rate }\end{array}$ & $\begin{array}{l}\text { Forming load and Material flow } \\
\text { characteristics }\end{array}$ & Yes \\
\hline $\begin{array}{l}\text { Chen et al } \\
\text { [69] }\end{array}$ & $\begin{array}{l}\text { Modelling of spin forming } \\
\text { of D6AC Alloy tube }\end{array}$ & $\begin{array}{c}\text { ANSYS/LS } \\
\text { DYNA }\end{array}$ & Thickness reduction & $\begin{array}{c}\text { Forming loads, Von Mises stress } \\
\text { and plastic strain }\end{array}$ & No \\
\hline $\begin{array}{l}\text { D'Annibale } \\
\text { et al [70] }\end{array}$ & $\begin{array}{c}\text { Modelling of flow forming } \\
\text { of Aluminum alloy } \\
6060 \text { Tubular structure }\end{array}$ & $\begin{array}{l}\text { PAM- } \\
\text { STAMP }\end{array}$ & $\begin{array}{l}\text { Feed rate, thickness } \\
\text { reduction }\end{array}$ & $\begin{array}{l}\text { Axial elongation, External } \\
\text { diameter, Final thickness, } \\
\text { Temperature distribution, Von- } \\
\text { Mises stress }\end{array}$ & Yes \\
\hline $\begin{array}{l}\text { Hwang et al } \\
\text { [71] }\end{array}$ & $\begin{array}{l}\text { Modelling of Aluminum } \\
\text { wheel forming }\end{array}$ & $\begin{array}{l}\text { SHAPE- } \\
\text { RR }\end{array}$ & $\begin{array}{c}\text { Head stock load, feed } \\
\text { rate, radial } \\
\text { compression, } \\
\text { geometry of rollers }\end{array}$ & Geometrical accuracy (Bulging) & Yes \\
\hline
\end{tabular}

reduction. Though mandrel can be undersized to counter the effect of diametric growth, minimization of the diametric growth by controlling $\mathrm{S}: \mathrm{L}$ ratio is an improved technique.

\subsection{Cracking}

Rajan and Narasimhan [73] have observed cracks in flow formed SAE4130 shell subsequent to pressure testing and dimensional accuracy check. Long, sharp, longitudinal through wall crack was observed during such cases. Inclusions at hard particle boundary results into huge stress concentrations and subsequently when such tube is subjected to $90 \%$ thickness reduction without any intermediate annealing, de-cohesion in mechanical bond is observed between particle and matrix. Such de-cohesion leads to cracking of flow formed tube. Further, few internal cracks were also observed on the mandrel side of tube surface for few hardened and tempered preforms. They opined that large number of inclusions present in the non-electro-slag refined raw material causes such cracks. Under such tensile stresses, inclusions serve as initiation sites leading to crack formation during forming or subsequent pressure testing. Such failures are similar to central burst as observed by Kalpakjian and Rajagopal [75].

\subsection{Fish scaling}

Failure mode such as fish scales was detected in flow formed of SAE 4130 steel tubes [73]. Fish scales were generally evident during final passes. The fish scaling may be attributed to the non-uniform grain size (possibly owing to inappropriate heat treatment), an occurrence of inclusions (that causes non-uniform deformation) and residual stresses during the process [76]. Hence, controlling for grain size is of prime importance and finer grain sizes are not preferred in cold forming, whereas coarser grain sizes causes fish scaling and cracking. Under some nondesirable parameter combination such as low roller entry angle, lower tip radius and low feed rate material build up in front of the roller may be observed. This might have led to fish scale formation (figure 14) and eventual cracking of flow formed tube [75].

\subsection{Material build-up}

The problem of material build-up [77] ahead of rollers is more evident in softer materials such as Aluminium. Tube defects such as material build-up ahead of the forming rollers can be avoided by minimizing the roller axial force [77]. They have carried out analysis to reduce the axial

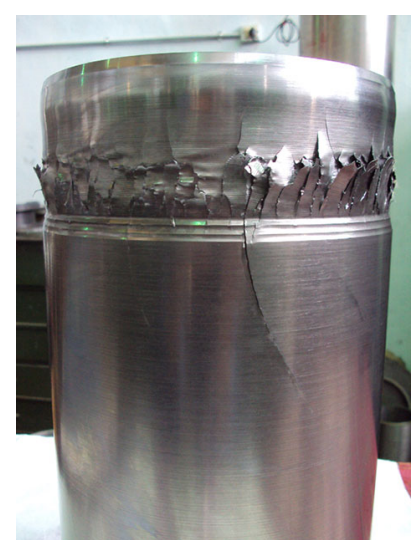

Figure 14. Flow-formed tubes with fish scales. 
force using the upper bound method to arrive at optimum roller entry angle during flow forming process. They opined optimal angle of attack minimizes axial force during the process, thus resulting in the minimized material build up. The same has been verified by elastic plastic FEM simulations also.

\section{Future research directions in flow forming}

Some of the critical areas on which research on flow forming is going on are indicated below.

(a) Optimization of process parameters: Due to the inherent advantages associated with the process, it has found larger acceptability in defence, aerospace and automobile industries. However, quality of the finished products demands the proper selection of inputs. Further, there is no established guideline for the selection of process parameters. Hence, we need highly skilled operator to run the machine. Most of the time, parameters are set through several numbers of initial trials. In this process, a considerable volume of man, as well as machine hour is lost, leading to loss of productivity and non-optimum utilisation of resources. Thus, the establishment of flow forming process parameter for any new product is not only time consuming but also a cost-intensive procedure. Also, the process involves large-scale, expensive machinery and associated tooling. Therefore, there is a need for a decision-making tool for automating such a complicated process.

(b) Improvement of formability: There is less literature concerning flow forming capabilities of various metals such as Aluminum and Titanium alloys. These metals are very hard to form and exhibit high spring back after cold forming. Aging or stress relief operations may be performed to reduce this. However, decision on a proper stress-relief cycle is the main key in this regard with proper tool setting. Also, suitable thermal as well as thermo-mechanical treatment need to be established to preprocess the raw materials.

(c) Forming of hard-to-deform materials: Some of the materials such as Aluminum and Titanium alloys (AA24345 and Ti-6Al-4V alloys) are very hard to deform. A proper mechanism is to be developed to make them amenable to flow form and separate tooling need to be developed to carry out experimental trials as well as on-line monitoring of the process parameters.

(d) Force measurement during forming: It has been observed that the axial and radial stress on the material plays important role in flow forming. However, it is very difficult to measure them experimentally. It should be carried out with proper arrangement so that the process is controlled.

\section{Conclusions}

In this paper, various principles, techniques and latest development of flow forming have been reviewed. This paper gives an introduction to the process, briefly describes advantages of the process, tooling and parameter used in the process. Various methods of estimation of power and forces, effects of process variables and general defects in flow forming process have been covered in this paper. Application of DOE to built input and output relationship of flow forming process parameters has also been briefly described in this paper. This paper also describes the need of FE simulation of the flow forming process. It aims at the identification of the important process parameters which are responsible for this process. From the literature survey it has been observed that attention is required on the following factors during FE simulation: Selection of Models (material properties of the workpiece and rollers), analysis of contact problems (consideration of different contact surfaces and friction characteristics of those surfaces), types of mesh and number of elements, software selection (Explicit or Implicit).

Future research in this field may be directed towards the manufacturing techniques for parts with complex geometrical features, shells with improved dimensional and form tolerances and asymmetric components. Accurate estimation of required power/forces and the optimization of process parameters to improve the product quality (minimization of ovality and bulge) and minimize the power/forces necessary for the improvement of machine tool design may be of prime future interest.

Efforts may be directed towards the development of an analytical model for prediction of geometrical parameters such as circularity of cross-section, a variation of thickness and mean diameter of the flow formed tube to ensure future development of the process.

Funding Funding was provided by Defence Research and Development Organisation (Grant No. DRDL/24/08P/13/0662/41949).

\section{References}

[1] Wong C C, Dean T A and Lin J 2003 A review of spinning, shear forming and flow forming processes. Int. J. Mach. Tools Manuf. 43: 1419-1435

[2] Sivanandini M, Dhami S S and Pabla B S 2012 Flow forming of tubes-A review. Int. J. Sci. Eng. Res. 3(5): 1-11

[3] Chang S C, Huang C A, Yu S A, Chang Y, Han W C, Shieh T S, Chung H C, Yao H T, Shyu G D, Hou H Y, Wang C C and Wang W S 1998 Tube spinnability of AA2024 and 7075 aluminium. J. Mater. Process. Technol. 80-81: 676-682

[4] https://leifeldms.com/en/our-offering/machine-series/st-ser ies/ [accessed 08-04-2017]

[5] http://www.iktech.kr/html/hi_content1.php?hi_num=0101 [accessed 08-04-2017] 
[6] http://mjcengineering.com/machines/flow-formingmachines/mjc-f450-2000-4/ [accessed 08-04-2017]

[7] www.denn.es/index.php/en/technologies/flow-forming [accessed 08-04-2017]

[8] http://www.repkon.com.tr/en/machines-flow-forming.html [accessed 08-04-2017]

[9] Davidson M J, Balasubramanian K and Tagore G R N 2008 An experimental study on the quality of flow-formed AA6061 tubes. J. Mater. Process. Technol. 203(1-3): 321-325

[10] Srinivasulu M, Komaraiah M and Prasada Rao C S K 2012 Experimental investigations to predict mean diameter of the AA6082 tube in flow forming process-A DOE approach. IOSR J. Eng. (IOSRJEN), 2(6): 52-60

[11] Podder B, Mondal C, Gopi G, Ramesh Kumar K and Yadav D R 2011 Effect of cold flow forming deformation on the tensile properties of $15 \mathrm{CrMoV} 6$ steel. In: Proceeding of 2011 International Conference on Mechanical and Aerospace Engineering (CAME 2011), New Delhi, India, pp. 604-606

[12] Rajan K M, Deshpande P U and Narasimhan K 2002 Effect of heat treatment of preform on the mechanical properties of flow formed AISI 4130 steel tubes-A theoretical and experimental assessment. J. Mater. Process. Technol. 125-126: 503-511

[13] Venkateshwarlu G, Ramesh Kumar K and Janardhan Reddy T A 2016 Experimental study of flow forming process parameters on thickness variation of aluminium alloy AA6061 tubes. Int. J. Lat. Res. Eng. Technol. 2(10): 33-40

[14] Ram Mohan T and Misra R 1970 Studies on power spinning of tubes. Int. J. Prod. Res. 10(4): 351-364

[15] Hayama M and Kudo H 1979 Analysis of diametrical growth and working forces in tube spinning. Bull. Jpn. Soc. Mech. Eng. 22 (167): 776-784

[16] Wang T, Wang Z R, Wang Q, Zhao Y and Wang S 1989 The slipline fields of thickness-reduction spinning and the engineering calculation of the spinning forces. In: Proceedings of the Fourth International Conference on Rotary Forming. 135-139: pp. 89-93

[17] Singhal P R, Saxena P K and Prakash R 1990 Estimation of power in the shear spinning of long tubes in hard-to-work materials. J. Mater. Process. Technol. 23 (1): 29-40

[18] Park J W, Kim Y H and Bae W B 1997 Analysis of tube spinning processes by the upper bound stream function method. J. Mater. Process. Technol. 66 (1-3): 195-203

[19] Paunoiu V, Nicoara D and Teodorescu M 1999 A general upper bound method for forces calculation in tube spinning process. In: Proceedings of the Sixth ICTP September 19-24, Advanced Technology of Plasticity. 1: pp. 109--1100

[20] Sukhwinder Singh Jolly and Bedi D S 2010 Analysis of power and forces in the making of long tubes in hard-to-work materials. In: Proceeding of the world congress on Engineering (WCE), Vol II, London, UK

[21] Muammer Koc and Taylan Altan 2002 Prediction of forming limits and parameters in the tube hydroforming process. Int. J. Mach. Tool. Manuf. 42(1): 123-138

[22] Lee K S and Lu L 2001 A study on the flow forming of cylindrical tubes. J. Mater. Process. Technol. 113(1-3): 739-742

[23] Rotarescu M I 1995 A Theoretical analysis of tube spinning using balls. J. Mater. Process. Technol. 54(1-4): 224-229

[24] Banerjee P, Kundu R, Singh M, Dubey P K and Hui N B 2016 FE based simulation of forward flow forming process. Int. J. Res. Mech. Eng. 4(2): 1-5
[25] Mali S and Joshi S S 2015 Three-dimensional simulation of staggered flow forming process. Int. J. Manu. Technol. Manag. 29(5-6): 324-346

[26] JIANG Shu-yong, ZHENG Yu-feng, REN Zheng-yi and LI Chun-feng 2009 Multi-pass spinning of thin-walled tubular part with longitudinal inner ribs. Trans. Nonferrous Met. Soc. China 19(1): 215-221

[27] Yang $\mathrm{Yu}$ and $\mathrm{Xu}$ Hongji 2010 Finite element analysis of power spinning and spinning force for tube parts. Int. J. Adv. Sci. Technol. 20: 53-59

[28] Zoghi H, Arezoodar A F and Sayeaftabi M 2013 Enhanced finite element analysis of material deformation and strain distribution in spinning of $42 \mathrm{CrMo}$ steel tubes at elevated temperature. Mater. Des. 47: 234-242

[29] Liu C-H 2007 The simulation of the multi-pass and die-less spinning process. J. Mater. Process. Technol. 192-193: 518-524

[30] Xia Q X, Cheng X Q, Hu Y and Ruan F 2006 Finite element simulation and experimental investigation on the forming forces of $3 \mathrm{D}$ non-axisymmetrical tubes spinning. Int. J. Mech. Sci. 48(7): 726-735

[31] Wu W T, Li G J, Tang J P and Altan T 1994 Finite element analysis of three- dimensional metal flow in cold and hot forming processes. CIRP Ann. Manuf. Technol. 43(1): 235-239

[32] Mehta B V, Ibrahim A Z, Gunasekera J S and Buijk A 2001 3D flow analysis inside shear and streamlined extrusion dies for feeder plate design. J. Mater. Process. Technol. 113(1-3): 93-97

[33] Huang L, Zeng R, Zhang X and Li J 2014 Study on plastic deformation behaviour of hot splitting spinning of TA15 titanium alloy. Mater. Des. 58: 465-474

[34] Srinivasulu M, Komaraiah M and Rao C S K P 2012 Experimental studies on the characteristics of AA6082 flow formed tubes. J. Mech. Eng. Res. 4(6): 192-198

[35] Jahazi M and Ebrahimi G 2000 The influence of flowforming parameters and microstructure on the quality of D6AC steel. J. Mater. Process. Technol. 103(3): 362-366

[36] Molladavoudi H R and Djavanroodi F 2011 Experimental study of thickness reduction effects on mechanical properties and spinning accuracy of aluminium 7075-O, during flow, forming. Int. J. Adv. Manuf. Technol. 52(9): 949-957

[37] Fazeli A R and Ghoreishi M 2009 Investigation of effective parameters on surface roughness in thermo-mechanical tube spinning process. Int. J. Mater. Form. 2(4): 261-270

[38] Gur M and Tirosh J 1982 Plastic flow instability under compressive loading during shear spinning process. J. Eng. Ind. 104(1): 17-22

[39] Podder B, Mondal C, Ramesh Kumar K and Yadav D R 2012 Effect of preform heat treatment on the flow formability and mechanical properties of AISI4340 steel. Mater. Des. 37: 174-181

[40] Malina J, Jirkova $\mathrm{H}$ and Masek B 2008 Optimization of technological parameters of flow forming process. In: Annals of DAAAM for 2008 \& Proceedings of 19th International DAAAM Symposium, pp. 783-784

[41] Rao L M, Rao T V L N, Ramana M V and Rao C S K P 2008 Study on the Influence of flow forming parameters of maraging steel tubes. IE(I) J. PR 89: 10-13

[42] Bairaju M K, Kiran Kumar K and Chand K 2016 Optimization of process parameters for the production of 
seamless rocket motor tube by flow forming process. Int. J. Innov. Eng. Res. Technol. 3(8): 70-80

[43] Venkateshwarlu G, Ramesh Kumar K, Janardhan Reddy T A and Gopi G 2013 Experimental investigation on spinning of aluminium alloy 19500 cup. Int. J. Eng. Sci. Innov. Technol. (IJESIT) 2(1): 357-363

[44] Davidson M J, Balasubramanian K and Tagore G R N 2008 Experimental investigation on flow-forming of AA6061 alloy-A Taguchi approach. J. Mater. Process. Technol. 200(1-3): 283-287

[45] Fazeli Nahrekhalaji A R, Ghoreishi M and Tashnizi E S 2010 Modelling and investigation of the wall thickness changes and process time in thermo-mechanical tube spinning process using design of experiments. Engineering 2: 141-148

[46] Davidson M J, Balasubramanian K and Tagore G R N 2008 Surface roughness prediction of flow-formed AA6061 alloy by design of experiments. J. Mater. Process. Technol. 202(1-3): 41-46

[47] Abedini A, Ahmadi S R and Doniavi A V 2014 Roughness optimization of flow formed tubes using the Taguchi method. Int. J. Adv. Manuf. Technol. 72(5-8): 1009-1019

[48] Jalali Aghchai A, Razani N A and Mollaei Dariani B 2012 Flow forming optimization based on diametral growth using finite element method and response surface methodology. Proc. Inst. Mech. Eng. Part B: J. Eng. Manuf. 226(12): 1-11

[49] Chen C, Ou J-H and Hsu C-J 2012 Simulation analysis of shell aluminium alloy tube for neck-in spinning process. WSEAS Trans. SYS. 11(8): 385-397

[50] Razani N A, Jalali Aghchai A and Mollaei Dariani B 2011 Experimental study on flow forming process of AISI 321 steel tube using the Taguchi method. Proc. Inst. Mech. Eng. Part B: J. Eng. Manuf. 225(11): 2024-2031

[51] Razani N A, Abdolhossein Jalali A and Mollaei Dariani B 2014 Flow-forming optimization based on hardness of flowformed AISI321 tube using response surface method. Int. J. Adv. Manuf. Technol. 70(5-8): 1463-1471

[52] Guo X, Li B, Jin K, Wang H, Wan B and Tao J 2017 A simulation and experiment study on paraxial spinning of Nibased superalloy tube. Int. J. Adv. Manuf. Technol. 93(9-12):4399-4407

[53] Wong C C, Danno A, Tong K K and Yong M S 2008 Cold rotary forming of thin wall component from flat disc blank. $J$. Mater. Process. Technol. 208(1-3): 53-62

[54] Li K, Hao N, Lu Y and Xue K 1998 Research on the distribution of the displacement in backward tube spinning. $J$. Mater. Process. Technol. 79(1-3): 185-188

[55] Song X, Fong S F, Oon S R and Danno A 2014 Diametrical growth in forward flow forming process. Int. J. Adv. Manuf. Technol. 71(1): 207-217

[56] Cho J, Jung Y, Lee M and Joun M 2014 Computationally efficient finite element model for simulating a chipless flow forming process. Int. J. Mater. Prod. Technol. 48(1-4): 258-269

[57] Sinde H, Mahajan P, Singh A K, Sing R and Narasimhan K 2016 Process modelling and optimization of the staggered backward flow forming process of maraging steel via finite element simulations. Int. J. Adv. Manuf. Technol. 87(5-8): $1851-1864$

[58] Novella M F, Ghiotti A, Bruschi S and Capuzzo R 2016 Numerical modelling of AlSi7 tubular components flow formed at elevated temperature. Key Eng. Mater. 716: 753-761
[59] Hauk S, Altan T and Vazquez V H 2000 Finite element simulation of the flow splitting-process. J. Mater. Process. Technol. 98(1): 70-80

[60] Hua F A, Yang Y S and Zhang Y N 2005 Three dimensional finite element analysis of tube spinning. J. Mater. Process. Technol. 168(1): 68-74

[61] Razavi H and Biglari F R and Torabkhani A 2005 Study of strains distribution in spinning process using FE simulation and experimental work. In: International Congress on Manufacturing Engineering, Tehran, pp. 1-9

[62] Sebastiani G, Brosius A, Ewers R, Kleiner M and Klimmek C 2006 Numerical investigation on dynamic effects during sheet metal spinning by explicit finite element analysis. $J$. Mater. Process. Technol. 177(1-3): 401-403

[63] Parsa M H, Pazooki A M A and Ahmadabadi M N 2009 Flow forming and flow formability simulation. Int. J. Adv. Manuf. Technol. 42(5): 463-473

[64] Xintian L, Changhong L, Lihui Z, Hu H, Xiaoyong Z and Xinyi S 2009 The finite element method applying in the flow forming. In: Proceedings of Computational Intelligence and Security Conference, pp. 556-558

[65] Qian B, Yang H and Zhan M 2008 Finite element modelling of power spinning of thin walled shell with hoop inner rib. Trans. Nonferrous Met. Soc. 18(1): 6-13

[66] Quigley E and Monaghan J 2002 Enhanced finite element models of metal spinning. J. Mater. Process. Technol. 121(1): 43-49

[67] Quigley E and Monaghan J 2002 The finite element modelling of conventional spinning using multi-domain models. J. Mater. Process. Technol. 124(3): 360-365

[68] Wong C C, Dean T A and Lin J 2004 Incremental forming of solid cylindrical components using flow forming principles. J. Mater. Process. Technol. 153-154: 60-66

[69] Cheng-Shun Chen, Jen-Hsin Ou and Huei-Guo Hu 2012 Simulation analysis of spinning forming of D6AC ultrahighstrength low-alloy steel. Int. J. Mech. 6(3): 187-194

[70] D'Annibale A, Di Ilio A, Paoletti A, Paoletti D and Sfarra S 2017 The combination of advanced tools for parameters investigation and tools maintenance in flow forming process. Procedia CIRP 59: 144-149

[71] Hwang Y S O, Kim N and Lee C 2015 Numerical investigation of the effect of process parameters during aluminium wheel flow-forming. J. Mech. Eng. 61(7-8): 471-476

[72] Houillon M, Massoni E, Ramel E and Loge R E 2007 3D FEM simulation of flow forming process using Lagrangian and ALE methods. AIP Conf. Proc. 908(1): 257-262

[73] Rajan K M and Narasimhan K 2001 An Investigation of the development of defects during flow forming of high strength thin wall steel tubes. Pract. Fail. Anal. 1(5): 69-76

[74] Sortais H C, Kobayashi S and Thomsen E G 1963. Mechanics of conventional spinning. J. Eng. Ind. 85(4): 346-350

[75] Kalpakjian S and Rajagopal S 1982 Spinning of tubes: A review. J. Appl. Met. Work. 2(3): 211-223

[76] Dieter G E 1988 Mechanical Metallurgy. UK: McGraw Hill. 3rd ed.

[77] Kim N, Kim H and Jin K 2013 Minimizing the axial force and the material build-up in the tube flow forming process. Int. J. Preci. Eng. Manuf. 14 (2): 259-266 